\title{
Analysis on Medical Cost Control in Chongqing Public Hospitals from 2011 to 2015
}

\author{
Weiwei Liu ${ }^{1}$ Shan $\mathrm{He}^{2}$ Xin Zhao ${ }^{3}$ Fang Tan ${ }^{4, *}$ \\ ${ }^{1}$ School of Public Health and Management, Chongqing Medical University, Chongqing 400016, China; \\ ${ }^{2}$ School of Nursing, Chongqing Medical University, Chongqing 400016, China \\ ${ }^{3}$ Chongqing Collaborative Innovation Center for Functional Food, Chongqing University of Education, Chongqing \\ 400067, China \\ ${ }^{4}$ Department of Public Health, Our Lady of Fatima University, Valenzuela 838, Philippines \\ *Corresponding author. Email: tanfang@foods.ac.cn
}

\begin{abstract}
Based on the analysis of outpatients and inpatients of public hospitals at all levels in Chongqing from 2011 to 2015, this paper combined with a new round of public hospitals reform which beyond the increased rate of medical expenses and the larger proportion of drugs, accounted for a further policy recommendation. The total income balance of $2011-2015$ in 16 public hospitals randomly collected in Chongqing, including the related key indicators: the outpatients and inpatients medical expenses per capita, the ratio of drug, which were calculated over the past five years. The proportion of drugs in sampled 16 hospitals in 2011 - 2015 were increased year by year, with an average increase rate of $32.82 \%$. The outpatient and inpatient's drug ratio were above $38 \%$ in all level of public hospitals; The average OP expenses per capita, respectively by $8.94 \%$ and $8.58 \%$ growth rate in secondary and tertiary hospitals. In primary hospitals the average inpatient expenses per capita growth rate was $8.39 \%$ during survey years. A new round reform of public hospitals in Chongqing has implemented a policy of primary consultation and two-way referral at the grassroots level.
\end{abstract}

Keywords: public hospital, outpatient expenses, inpatient expenses, medical expenses

\section{INTRODUCTION}

The growth of medical expenses in public hospitals has always been the core issue in the reform of China's medical and health system, and also the focus of the public's attention ${ }^{[1]}$, especially the medical expenses and drug expenses. In August 2017, the notice on printing and distributing the comprehensive reform implementation plan of public hospitals in Chongqing (hereinafter referred to as the notice) issued by Chongqing Municipality proposed that all kinds of public hospitals should comply with the reform needs, strictly control the growth rate of medical expenses within $10 \%$, and reduce the proportion of drugs to less than $30 \%$. In this study, the data of 16 sampling hospitals and public hospitals at all levels in Chongqing in the past five years were analyzed to understand the medical expenses of different levels of public hospitals. In order to reduce the burden of medical expenses of the public, relieve the pressure of medical treatment of public hospitals at all levels, simultaneously modify the proportion of medical insurance, this paper will carry out a new round of public hospital reform research in Chongqing.

\section{DATA AND METHODS}

\subsection{Data Source}

In this study, 16 public hospitals in Chongqing were selected as sample hospitals for investigation and study, to understand the drug revenue and expenditure and outpatient and inpatient revenue and expenditure of each sample hospital in 2011-2015, and to analyze the growth of medical expenses of public hospitals in Chongqing Based on the data of Chongqing Health Statistics Yearbook and medical expenses of Chongqing Health and Family Planning Commission. In order to make the survey data comparable, 16 hospitals with the strongest comprehensive ability and 439 public hospitals in 38 districts and counties were selected as the research objects in this study to ensure that the new round of public hospital reform policy in Chongqing can be carried out steadily.

\subsection{Research Methods}

Based on the data collection of hospitals and patients in Chongqing from 2011 to 2015, including the statistics of 
From 2011 to 2015, the total medical revenue of 16 public hospitals in Chongqing increased from 6.141 billion yuan in 2011 to 12.426 billion yuan in 2015 , with an average annual growth rate of $19.27 \%$, showing a gradual upward trend. In the past five years, the average annual growth rate of outpatient and inpatient income is $22.14 \%$ and $17.41 \%$ respectively; the average annual growth rate of outpatient part and inpatient part of drug cost is $20.25 \%$ and $12.91 \%$ respectively. The sum of the 16 public hospitals surveyed showed a downward trend, especially after 2011, the hospital balance decreased sharply, from 6.141 billion yuan in 2011 to 1.76 billion yuan in 2015 . On the contrary, in the past five years, the sum up of drugs in public hospitals has increased year by year, with an average annual increase of $32.82 \%$ (Table 1 ).

\subsection{Outpatient and inpatient income and expenditure of 16 municipal public hospitals in Chongqing}

Table 1 medical balance of 16 municipal public hospitals in Chongqing (100 million yuan)

\begin{tabular}{|c|c|c|c|c|c|c|}
\hline Year & $\begin{array}{c}\text { Outpatient } \\
\text { income }\end{array}$ & $\begin{array}{c}\text { Outpatient } \\
\text { drug revenue }\end{array}$ & $\begin{array}{c}\text { Inpatient } \\
\text { income }\end{array}$ & $\begin{array}{c}\text { Inpatient drug } \\
\text { revenue }\end{array}$ & $\begin{array}{c}\text { Sum up of } \\
\text { medical treatment }\end{array}$ & Drug sum up \\
\hline 2011 & 23.03 & 12.10 & 38.37 & 15.10 & 61.41 & 2.05 \\
2012 & 31.10 & 16.11 & 47.84 & 18.35 & 42.24 & 4.83 \\
\hline 2013 & 37.48 & 19.53 & 55.75 & 20.64 & 19.53 & 6.25 \\
\hline 2014 & 25.33 & 23.26 & 67.60 & 24.18 & 16.86 & 6.46 \\
\hline 2015 & 51.25 & 25.30 & 72.92 & 24.54 & 17.60 & 6.38 \\
\hline
\end{tabular}

\subsection{Outpatient and inpatient medical expenses of 16 municipal public hospitals in Chongqing}

In the survey year, the average medical expenses per time of outpatients increased year by year, from 284.59 yuan in 2011 to 409.80 yuan in 2015 , with an annual growth rate of $9.54 \%$; in terms of hospitalization, from 12131.25 yuan in 2011 to 15184.07 yuan in 2015 , with an annual growth rate of $5.77 \%$; in terms of discharge, the average medical expenses per day of outpatients increased by $9.71 \%$, with an annual growth rate similar to that of outpatients All the medical expenses were similar. In terms of drug expenses, it can be seen that in the past five years, the proportion of outpatient drugs is heavier, accounting for nearly half of the average secondary medical expenses of outpatient patients; the proportion of inpatient drugs is more than $30 \%$ (Table 2 and 3).

Table 2 outpatient medical expenses of patients in 16 municipal public hospitals in Chongqing (yuan, \%)

\begin{tabular}{|c|c|c|c|}
\hline \multirow{2}{*}{ Year } & \multicolumn{3}{|c|}{ Outpatient } \\
\cline { 2 - 4 } & $\begin{array}{c}\text { Average secondary medical } \\
\text { expenses of outpatients }\end{array}$ & $\begin{array}{c}\text { Outpatient } \\
\text { medicine fee }\end{array}$ & Drug proportion \\
\hline 2011 & 284.59 & 149.43 & 52.50 \\
2012 & 292.76 & 151.67 & 51.81 \\
\hline 2013 & 361.10 & 188.17 & 52.11 \\
\hline 2014 & 388.69 & 199.49 & 51.32 \\
\hline 2015 & 409.80 & 201.85 & 49.26 \\
\hline
\end{tabular}

Table 3 inpatient medical expenses of patients in 16 municipal public hospitals in Chongqing (yuan, \%)

\begin{tabular}{|c|c|c|c|c|}
\hline Year & \multicolumn{3}{|c|}{ Inpatient } & $\begin{array}{c}\text { Average daily hospitalization } \\
\text { medical expenses of } \\
\text { discharged patients }\end{array}$ \\
\hline 2011 & $\begin{array}{c}\text { Per capita medical } \\
\text { expenses of } \\
\text { inpatients }\end{array}$ & $\begin{array}{c}\text { Inpatient drug } \\
\text { fee }\end{array}$ & Drug proportion & 949.30 \\
2012 & 12131.25 & 4772.79 & 39.34 & 1027.51 \\
\hline 2013 & 13026.25 & 4995.90 & 38.35 & 1167.67 \\
\hline 2014 & 14208.41 & 5260.56 & 37.02 & 1306.16 \\
\hline 2015 & 14929.43 & 5340.93 & 35.77 & 1375.27 \\
\hline
\end{tabular}




\subsection{Medical expenses of general public hospitals at all levels in Chongqing}

The average medical expenses of outpatient and inpatient in the first-class public hospitals in Chongqing are lower than those of other medical institutions. It mainly provides routine medical services for ordinary patients with mild illness. Medical instruments and equipment are conventional and limited, and patients mainly dispense drugs. Therefore, the increase of its drug proportion is higher than that of other hospitals ${ }^{[2]}$. In terms of outpatient service, the outpatient service cost of the first level hospital has been well controlled in the past five years. The average annual growth rate of outpatient service cost of the second level hospital and the third level hospital is $8.94 \%$ and $8.58 \%$, respectively. In terms of hospitalization, the average annual growth rate of per capita medical expenses of firstclass hospitals is as high as $8.39 \%$, and that of second-class and third-class hospitals is $7.00 \%$ and $3.48 \%$, respectively. It can be seen that the per capita medical expenses of thirdclass hospitals have been well controlled in recent years. The proportion of drugs in hospitals at all levels has exceeded $38 \%$ in the past five years. The absolute values of the average secondary medical expenses of outpatients and the average medical expenses of inpatients in the tertiary hospital are the highest, as shown in Table 4-6.

Table 4 medical expenses and composition of public hospitals at all levels in Chongqing (yuan, \%)

\begin{tabular}{|c|c|c|c|}
\hline \multirow{2}{*}{ Year } & \multicolumn{3}{|c|}{ Primary hospital } \\
\cline { 2 - 4 } & $\begin{array}{c}\text { Average outpatient } \\
\text { medical expenses }\end{array}$ & $\begin{array}{c}\text { Per capita medical } \\
\text { expenses in hospital }\end{array}$ & Drug proportion \\
\hline 2011 & 123.48 & 2889.90 & 38.92 \\
2012 & 193.39 & 3233.40 & 39.58 \\
\hline 2013 & 127.21 & 3889.27 & 45.00 \\
\hline 2014 & 160.6 & 4081.04 & 44.06 \\
\hline 2015 & 171.19 & 3988.59 & 44.98 \\
\hline
\end{tabular}

Table 5 medical expenses and composition of public hospitals at all levels in Chongqing (yuan, \%)

\begin{tabular}{|c|c|c|c|}
\hline \multirow{2}{*}{ Year } & \multicolumn{3}{|c|}{ Secondary Hospital } \\
\cline { 2 - 4 } & $\begin{array}{c}\text { Average outpatient } \\
\text { medical expenses }\end{array}$ & $\begin{array}{c}\text { Per capita medical } \\
\text { expenses in hospital }\end{array}$ & Drug proportion \\
\hline 2011 & 164.28 & 5010.56 & 46.28 \\
2012 & 173.61 & 5596.72 & 44.09 \\
\hline 2013 & 200.60 & 6133.01 & 44.63 \\
\hline 2014 & 221.44 & 6434.63 & 42.93 \\
\hline 2015 & 231.41 & 6566.17 & 40.25 \\
\hline
\end{tabular}

Table 6 medical expenses and composition of public hospitals at all levels in Chongqing (yuan, \%)

\begin{tabular}{|c|c|c|c|}
\hline \multirow{2}{*}{ Year } & \multicolumn{3}{|c|}{ Tertiary hospitals } \\
\cline { 2 - 4 } & $\begin{array}{c}\text { Average outpatient } \\
\text { medical expenses }\end{array}$ & $\begin{array}{c}\text { Per capita medical } \\
\text { expenses in hospital }\end{array}$ & Drug proportion \\
\hline 2011 & 252.64 & 11543.13 & 44.46 \\
2012 & 265.12 & 12102.95 & 44.11 \\
\hline 2013 & 311.50 & 12944.48 & 43.71 \\
\hline 2014 & 335.76 & 12907.03 & 42.64 \\
\hline 2015 & 351.12 & 13235.38 & 40.65 \\
\hline
\end{tabular}

\section{DISCUSSION}

\subsection{Cancel the drug markup fee and drug service fee in an all-round way, and implement the construction of "two ticket system"}

Since 2011-2015, the proportion of outpatient drugs in 16 municipal public hospitals in Chongqing has exceeded half of the total cost, and the proportion of inpatient drugs has exceeded 1 / 3 of the total cost, while the proportion of outpatient drugs in municipal public hospitals in Chongqing has occupied about half of the total cost, and the proportion of inpatient drugs has exceeded 2 / 5 of the total cost. The proportion of drugs required in the notice is far more than $30 \%$. In the early 1950 s, China began to implement the policy of increasing the price of drugs. The policy stipulates that the addition rate of Western medicine sold by the hospital shall not exceed $15 \%$, that of Chinese patent medicine shall not exceed $16 \%$, and that of Chinese herbal medicine shall not exceed $29 \%{ }^{[4]}$. After the 1980 s, due to the imperfect compensation mechanism of the medical 
levels. The treatment of acute and chronic diseases mainly points out the types of acute and chronic diseases. Family doctors mainly take chronic patients such as hypertension and diabetes as the contracting objects, carry out door-todoor and appointment services and other convenient services, to reverse the waste of medical service resources.

\section{ACKNOWLEDGMENT}

This work was supported by Technical Foresight and Institutional Innovation Project of Chongqing Science and Technology Commission (cstc2018jsyj-zcdxX0049); Scientific Research Projects of Chongqing Sports Bureau (A201807); Humanities and Social Sciences Research Project of Chongqing Education Committee (17SKG018)

\section{REFERENCES}

[1] L.Luo, H.Kong, F.Liu, Logical steps of medical and health system reform with effective control of medical expenses as the core, Proceedings of the Health policy research in China, Chinese Academy of Medical Sciences, 2009, pp :23-26.

[2] X.J.Liu, X.T.Wen, M.Y.Wu, Analysis on the current situation of medical expenses of outpatients and inpatients in public hospitals in Jiangxi Province, Proceedings of the Health resources in China, Journal of health resources, 2017, pp:65. DOI: 10.13688/j.cnki.chr.2017.16358

[3] D.Song, W.Yao, R.J.Yu, A new way to adjust the structure of hospital compensation, Proceedings of the Health resources in China, Journal of health resources, 2005, pp:112

[4] P.Y.Wang, J.L.Yang, J.Chen, Research on the growth of medical expenses in Gansu Province in 2010-2014 and the reasons, Proceedings of the China's health industry, National Health Industry Enterprise Management Association , 2016, pp: 1-2. DOI: 10.16659/j.cnki.16725654.2016.01.001

[5] J.Zhao, Y.X.Zhang, Q.X.Guo, Analysis on the control of medical expenses in Shanxi Province from 2013 to 2014, Proceedings of the , Health economy in China, Heilongjiang Health Development Research Center, 2016, pp:77-80 